\title{
La historia de la antropología como excusa: la influencia de la metodología en la disparidad historiográfica
}

\section{EL PROBLEMA DE LAS VERSIONES HISTORIOGRÁFICAS}

La necesidad de hacer historia de la antropología es algo evidente: cualquier disciplina necesita reconocerse a sí misma por su contraste con las demás, y la historia es el camino más adecuado para ello. Sin embargo, según se ha producido el desarrollo de la antropología, esta historia viene escrita de muy distinta forma. De aquí, la proliferación de historias de la antropología y la tradición diferente que cada una de ellas registra. La misma forma de narrar el progreso de la disciplina se ve modificada con el tiempo. Los motivos de estos cambios y los distintos caracteres que presentan los relatos históricos son variados. Las causas principales pertenecen a la sociología de la antropología, y tienen su raíz en el particular desarrollo de esta ciencia y su búsqueda de profesionalización: los intereses son múltiples y varían en importancia según el lugar y el tiempo.

Con frecuencia nos hemos sentido desconcertados ante las variadas versiones de la historia de la antropología que nos ofrecen los diferentes manuales y artículos. Cualquier episodio de aquélla puede llegar a adquirir matices contradictorios según la fuente consultada. Sin duda, tanto desde el punto de vista de la antropología como desde el de su historia, tal disparidad no puede ser menospreciada porque cada vez es más frecuente que el primer contacto del neófito con la materia tenga lugar a través de este tipo de obras; difícilmente se aceptará como digna de ser tomada en cuenta una disciplina cuya historia es el producto aparente del capricho del narrador.

Este trabajo intenta profundizar en una de las causas que han podido originar tal disparidad de versiones. Resultará evidente que, siendo los motivos que inciden en la redacción de las historias un factor psico-sociológico, no es necesario que se den aislados unos de otros, aunque lo específico de nuestro estudio nos obligue a presentarlo de esta forma. Por otro lado, establecer los motivos que han llevado a utilizar la historia de la antropología como excusa para exponer el propio punto de vista supone admitir implícitamente que las razones dadas a veces por sus autores no son las 
únicas; en la práctica, los motivos pueden ser vistos como condicionamientos que, a lo largo del tiempo, han influido en la historiografía de la antropología.

Nuestra actitud resulta legitimada si tenemos en cuenta que la historia de la antropología ha sido hasta los años sesenta un terreno de disputa menor; las polémicas no tenían lugar por el tema historiográficamente tratado, sino por la utilización que se deseaba hacer del mismo. Esto ha dado lugar a una especialidad donde reina el subjetivismo, carente hasta hace poco de un adecuado y fructífero debate centrado sobre sus propios intereses, y con la vista puesta en los de la disciplina que se trataba de historiar más que en la propia historia. El recurso a la historia de la antropología carecía de interés por sí mismo.

La nueva historiografía de la antropología surge en los años sesenta como un componente más de la historiografía científica. Comparte con ésta su interés por la historia real, alejada de las mistificaciones de las que son objeto las historias elaboradas por los mismos practicantes de cada disciplina. Acorde con ello, busca y elabora sus propias categorías, con frecuencia muy diferentes de las aceptadas por los propios científicos. A esto nos referimos cuando decimos que las razones dadas por los autores de los textos no necesariamente deben ser aceptadas como las únicas, ni siquiera como las más importantes que les han llevado a escribir tales textos. Es normal que el profesional de una disciplina posea un concepto historiográfico de la misma muy diferente del que tiene el historiador que contempla ésta desde una perspectiva menos familiar, más profesional. Lo que afirmamos ha sido descrito por un conocido antropólogo mediante una parábola etnográfica:

Creíamos al principio que los historiadores de la ciencia nos visitaban por sincero interés en nuestras tradiciones, para ser edificados con ellas como nosotros lo fuimos, y para recordarlas al resto del mundo y a la posteridad, para no ser olvidadas. Con el tiempo, sin embargo, pudimos descubrir que nuestros atentos visitantes no mantenían siempre nuestras estimaciones de valor. Se movían de un campamento a otro, y comparaban notas. Comprendimos que difícilmente podrían llegar a ser de los nuestros, si no se habían sometido a la misma iniciación (trabajo de campo), sin estar expuestos a nuestra dirección lo suficiente en sus correrías. Pero, desconcertantemente, estaban tranquilos y confiados en su propia dirección. Se apresuraban a decidir por sí mismos qué parte de nuestras estimaciones debía ser creída. Lo que para algunos de nosotros es una sencilla categoría de «el (glorioso/vergonzoso) pasado", ellos lo dividían y redistribuían en diferentes categorías propias, tales como «documentado», "valor a comprobar», «de poca confianza» y, a veces, «folklore». Lo que para algunos de nosotros es históricamente negro y blanco, con todo el agudo clamor de un bien cuadrado western, lo disimulaban dentro de abigarradas matizaciones en su mayor parte grises. A menudo llegaban a impugnar o disputar nuestros ancestros, interpolando antepa- 
sados de quien no teníamos memoria; atribuyendo nobles hechos e invenciones a hombres que no son héroes de la cultura, acerca de los cuales nunca oimos tales cosas; trazando líneas de descendencia en direcciones que no soportan nuestras presentes oposiciones segmentarias ${ }^{1}$.

Este juicio, hecho ante una situación experimentada como novedad, es el que permite distinguir ambos tipos de labor historiográfica: la familiar, hecha por los propios practicantes del gremio, y la profesional, realizada por historiadores. A lo anticuado de la primera de estas categorías ha aludido Kuhn: «la nueva historiografía no ha tocado las ciencias sociales. En estas materias, la literatura histórica, cuando existe, es producto exclusivo de los profesionales de la ciencia de que se trate» ${ }^{2}$.

La creciente importancia concedida a la historia de la antropología resulta confirmada por el incremento de los artículos y reseñas dedicados a este campo. Tal vez, si hemos de fijar una fecha, pueda señalarse el año 1968 como punto central en el que cristalizan las preocupaciones historiográficas, aunque desde el inicio de esa década ya estaba muy presente el interés por la historia. Sirva como ejemplo el órgano de la Asociación Antropológica Americana: American Antbropologist, que desde su fundación en 1888 recoge las tendencias predominantes en la antropología de los Estados Unidos. Una búsqueda a través de dicha revista nos permite apreciar lo que afirmamos. En 1968, por primera vez y como muestra de una creciente atracción por parte de los profesionales de la disciplina, la sección de reseñas de libros de American Antbropologist es ocupada en su primera parte por un apartado dedicado a historia de la antropología ${ }^{3}$, con reseñas de autores tan conocidos como A. I. Hallowell, Leslie A. White, George W. Stocking Jr., Fred Eggan, etc.; podríamos decir que la mayor parte de éstos representan el movimiento profesional en la historiografía de la antropología. Este mismo año se publican dos libros de enorme importancia, aunque por motivos bien distintos: el libro de Stocking, Race, Culture and Evolution. Essays in the History of Antbropology, y el de Harris, El desarrollo de la teoría antropológica. Una historia de las teorias de la cultura.

El libro de Stocking se compone de artículos que tratan temas diferentes pero unidos por una preocupación común: demostrar que es posible una

1 Dell Hymes, «On Studying the History of Anthropology», Regna Darnell (comp.), Readings in the History of Anthropology (New York: Harper \& Row, 1974), 297-303; 298. Original 1962.

2 Thomas S. KUHN, «Ciencia: Historia de la Ciencia», Enciclopedia Internacional de Ciencias Sociales (1974), 2, 313-321; p. 316. El subrayado es nuestro.

3 Book Reviews, «History of Anthropology», American Antbropologist, 70 (1968), 1183-1192. 
historiografía de la antropología basada en criterios historicistas, y alejada del carácter panfletario que es común a numerosos artículos y libros, donde lo histórico sólo es excusa para apoyar las virtudes de la propia escuela. La referencia al historicismo tiene el riesgo de utilizar un término cargado de connotaciones filosóficas. Pero su uso por el historiador norteamericano, consciente de las resonancias que la palabra puede despertar, sólo incluye un intento de investigar el pasado por el pasado ${ }^{4}$. El empleo de criterios historicistas en la historiografía de la antropología supone, en la práctica, una postura afectiva, no utilitaria, por parte del historiador. En la explicación que Stocking ofrece de lo que ha de ser una actitud historicista se produce la paradoja de que se entiende más de lo que se expresa, es decir, entendemos que el historicismo es la actitud de aproximación a la historia contraria al presentismo, y a partir de ello cada denuncia de lo que es presentismo supone una defensa de lo que ha de ser historicismo. Sin embargo, la explicación concreta de lo que es historicismo no preocupa tanto a Stocking. Una definición que puede resumir a grandes rasgos esta postura historicista es proporcionada al final de su ensayo: el historiador debe ocuparse de lo históricamente significante, «Pero hacer esto requiere una aproximación en términos de contexto, proceso, emergencia, reflexión y razonabilidad. Realmente, la idea principal de este ensayo es que esta meta requiere una orientación afectiva, historicista, que intenta "investigar el pasado por el bien del pasado". Por suspender el juicio como utilidad presente hacemos posible en última instancia este juicio» s.

El libro de Harris, por contra, hace de la militancia metodológica su mayor virtud, y no duda en servirse de la historia para apoyar sus tendencias materialistas; no obstante, su amplitud y el detalle que su autor demuestra al analizar la antropología de su país, hacen del libro una apasionante fuente de interés. En dicha obra podemos apreciar, además, el perfecto contrapunto al historicismo de Stocking; Harris no sólo hace una historia presentista sino que defiende las virtudes de ésta:

El historiador George Stocking se ha ocupado detenidamente de esta confusa oscilación de los evolucionistas entre los polos del idealismo y del materialismo filosóficos. Ante la existencia de mezclas eclécticas como las que hemos visto y ante el interés manifiesto que los evolucionistas mostraban por la tarea de reconstruir los estadios de la historia, Stocking llega a la conclusión de que las categorías filosóficas del idealismo y del materialismo no constituyen unas coor-

4 George W. Stocking, Jr., «On the Limits of "Presentism" and "Historicism" in the Historiography of the Behavioral Sciences», Race, Culture and Evolution. Essays in the Historiography of Anthropology (New York: The Free Press, 1968), 4. Original 1965.

Ibid., 12. 
denadas válidas para el estudio de la antropología del siglo XIX. Por esta razón previene a los antropólogos que se esfuerzan por comprender la historia de su disciplina de que «las polémicas de hoy pueden ofuscar nuestra comprensión histórica» (1965, p. 142). Mas a ello tendríamos que contestar sin ambages que en realidad ocurre lo contrario, que sólo los puntos polémicos del presente hacen posible nuestra comprensión de la historia. Para Morgan, para Tylor o para Spencer, el hecho de que ninguno de los evolucionistas clásicos ofreciera una explicación materialista (cultural) de la evolución sociocultural no tenía especial importancia ni significación. En cambio, para el antropólogo de hoy, que trata de conocer los fundamentos de la teoría contemporánea, ningún otro hecho tiene, retrospectivamente, tanta importancia como ése ${ }^{6}$.

El hecho de que el movimiento historiográfico haya surgido con más fuerza en Estados Unidos que en ningún otro lugar no es fruto de la casualidad: es en este país donde ha aparecido con una importancia creciente una nueva concepción de la historiografía de las ciencias, cuya figura más representativa tal vez sea el historiador de la física Thomas S. Kuhn. En el caso concreto de la historiografía de la antropología, ha sido éste precisamente quien ha señalado el interés de la labor acometida por un historiador de esta disciplina tan conocido como Stocking: «Las publicaciones preliminares de Stocking sobre la historia de la antropología americana proporcionan un ejemplo particularmente fecundo de la perspectiva que el historiador general puede aplicar a un campo científico cuyos conceptos y vocabulario sólo muy recientemente se han tornado esotéricos» ${ }^{7}$.

La importancia de Stocking y, en general, la de la nueva historiografía de la antropología de Estados Unidos es proporcional al nivel de profesionalización que la disciplina posee en ese país. La relación entre el número de profesionales dedicados a la antropología y la importancia que se presta a su historia, parece fuera de duda. Se trata de una correlación que ha sido señalada con anterioridad ${ }^{8}$; con ella se ha intentado explicar la escasez de historias de la antropología en nuestro país y la abundancia e importancia de las mismas en Estados Unidos. Este país puede servir como ejemplo de una mayor representación de la profesión antropológica, y, a la vez, confirmando lo que venimos manteniendo, modelo de dedicación historiográfica a la misma: «En Norteamérica se han hecho esfuerzos para dar un papel a la historiografía en la profesión antropológica. Primero, a

6 Marvin HaRris, El desarrollo de la teoria antropológica. Una bistoria de las teorias de la cultura (Madrid: Siglo XXI, 1978), 188. Original 1968.

7 Thomas S. KUHN, op. cit., 316.

8 Fermín del PINo DiAz, «Repercusiones de la nueva historiografía de las ciencias en el caso de la etnología: el problema de la profesionalización», Alcaveras, 4 (1984), 19-22, p. 19. 
nivel formativo, como muestran los cada vez más frecuentes cursos especiales de historia (separada del curso de teoría) que se dan a nivel introductorio, así como la aceptación de que se obtenga el título de antropólogo sin hacer trabajo de campo sobre una comunidad determinada» 9 .

Confirma esta correlación el hecho de que en nuestro país haya habido un gran aumento de la labor historiográfica en los últimos años: las primeras bibliografías de trabajos antropológicos en España y sobre España, incluían escaso número de trabajos sobre historia ${ }^{10}$; no obstante, podemos señalar que la situación está cambiando, como lo demuestran los recientes Boletines de Historia de la Antropología ${ }^{11}$, y las mismas bibliografías que figuran en obras que narran la historia de la antropología o del folklore a nivel regional ${ }^{12}$. Esta situación coincide con un nivel de institucionalización que, aunque posiblemente sea todavía insuficiente, la antropología española no había conocido con anterioridad (cátedras, dotación económica para investigaciones, consultas de organismos públicos, etc.). A la vez, en nuestro país no parece haber tenido lugar la resistencia de los Departamentos de Antropología americanos e ingleses para aceptar tesis doctorales sobre historia de la antropología, y conceder el título por este motivo; posiblemente porque hasta hace bien poco no existía ni esta última posibilidad. Conviene recordar a este respecto que, tal vez, Stocking y Darnell fueron de los primeros en Estados Unidos, y Llobera debió serlo en Inglaterra ${ }^{13}$.

La aceptación de esta especialización reviste gran importancia; no sólo permite una mayor objetividad en los planteamientos, sino que, además, otorga un carácter cualitativo que nunca habían alcanzado las historias de la antropología. Objetividad y calidad se unen en la búsqueda de una serie de problemas inabordables unos años antes. Con el reconocimiento acadé-

$9 \quad$ Ibid., 20.

10 Sólo por citar las más antiguas y conocidas: Isidoro MORENO NAVARro, «La antropología en Andalucía. Desarrollo histórico y estado actual de las investigaciones», Ethnica, I (1971), 107-44; Alfredo JIMÉNEZ y Elías ZAMORA, «Bibliografía de antropólogos españoles», Primera Reunión de Antropólogos Españoles, comp. Alfredo JIMÉNEZ (Universidad de Sevilla, 1975), 359-395; Joan PRAT, «Una aproximación a la bibliografía antropológica sobre España», Ethnica, 13 (1977), 129-171. Con un apéndice estadístico.

1 Boletín de Historia de la Antropología, I (1988; 35 pp.), 2 (1989; 50 pp.) y 3 (1990; 41 pp.).

12 José PÉrez VIDAL, Los estudios del Folklore canario (1880-1980) (Madrid: Excma. Mancomunidad de Cabildos de Las Palmas - Ministerio de Cultura, 1982); Ángel AGuirre BAZTÁ (comp.), La Antropología cultural en España.Un siglo de Antropología (Barcelona: P.P.U., 1986); Alberto GALVÁN TUdela, Islas Canarias. Una aproximación antropológica (Barcelona: Anthropos, 1987).

13 Fermín del PINO, op. cit., 20. 
mico de las tesis sobre historia de la antropología se concedía beligerancia a las nuevas interpretaciones de la historia de la disciplina ${ }^{14}$. Las explicaciones semibiográficas, basadas en el recuerdo cariñoso e idolatrado del maestro, son sustituidas por críticas serias y apoyadas en documentos con frecuencia olvidados por los antropólogos.

De esta manera se contribuye a dejar al descubierto muchos de los intereses que han guiado la investigación antropológica, y que de hecho todavía imperan en buena parte de sus practicantes. Algunas causas de la disparidad que muestran las historias de la antropología tienen su origen en factores tales como la importancia creciente de los profesionales dedicados a ella, la mayor especialización de éstos, la búsqueda de una tradición capaz de otorgar prestigio a la nueva ciencia, el nacionalismo, la lucha por señalar una tradición que favorezca los intereses metodológicos del que hace la historia, lograr una mayor atención del medio socio-político que provoque mejores oportunidades económico-administrativas para la nueva disciplina, la utilidad de un «registro» de datos para orientar a las nuevas promociones, el progreso de la disciplina, cuyo logro suele venir dado por la línea metodológica del historiador, etc.

A continuación nos ocuparemos de estudiar la influencia de la epistemología, de las creencias de escuela de cada autor, y sus efectos historiográficos. Se trata, en definitiva, de precisar cómo la mayor parte de las historias de la antropología son utilizadas para divulgar los puntos de vista metodológicos de sus autores sin necesidad de fundamentar éstos.

\section{HISTORIA Y METODOLOGf́a: UNA RELACIÓN INTERESADA}

La diversidad de opciones teóricas dentro de las ciencias sociales no es un secreto para nadie. Nuestra materia no es una excepción y sus profesionales se dividen en grupos de acuerdo con distintos ismos: funcionalismo, marxismo, estructuralismo, materialismo cultural, etc. Los grupos se constituyen y se separan continuamente, los ismos se entrecruzan, y lo que era un ejemplo de clara incompatibilidad entre el estructuralismo y el marxismo, desaparece para dar paso a un marxismo estructuralista el cual, a su vez, reclama su utilidad para la práctica revolucionaria ${ }^{15}$. No existe un único paradigma capaz de imponerse en antropología. Hoy en día, los intentos de imponer uno de los existentes proceden más del corazón que de

14 Ibid., 21.

15 Maurice GodELIER, Funcionalismo, estructuralismo y marxismo (Barcelona: Anagrama, 1976), 67. Original 1972. 
la razón; apelan a la necesidad de unirse en la búsqueda común, más que al convencimiento del razonamiento teórico.

En este ambiente tiene lugar la elaboración de historias con la finalidad explícita o implícita de mostrar el desarrollo de la teoría antropológica en la versión defendida. Lo que poseen estas historias en común es la defensa de su línea metodológica, que constituye tan sólo una parte de la antropología, como si a lo largo del tiempo hubiera sido la única existente. La denuncia de este tipo de hechos la ha realizado Jarvie: "Cientifismo, positivismo, materialismo cultural, rehúsan reconocer el progreso como tal cuando ocurre a menos que se conforme a sus ideas erróneas de lo que las teorías científicas deberían parecer» ${ }^{16}$.

Sin embargo, no sólo este tipo de opiniones metodológicas han tratado de realizar una historia a su medida, y, por otra parte, aunque Jarvie las incluye en un mismo grupo, estas corrientes de investigación resultan bien diferentes. La prueba de lo que afirmamos puede proporcionarla cualquier historia de la antropología; escojamos la de Lowie, durante tanto tiempo considerada paradigma del desarrollo histórico de la disciplina antropológica, y en absoluto calificable de cientifista, positivista o materialista. A pesar de su inicial declaración de intenciones: «El autor ha aspirado al mayor grado posible de objetividad en el análisis de opiniones teóricas, haciendo un esfuerzo por subrayar las aportaciones positivas de cada etnólogo aquí estudiado, más que sus deficiencias» ${ }^{17}$, Lowie no puede evitar reflejar su propia postura teórica y tomar como prejuicio epistemológico la búsqueda de leyes por parte de Durkheim: «Nuestro autor, a pesar de tener como meta primaria indicar la autonomía de la sociología, y a despecho de admitir solamente determinados procedimientos lógicos, como compatibles con la naturaleza de los datos sociológicos, no se puede librar como sus predecesores del prejuicio de que la nueva ciencia debe buscar leyes generales» ${ }^{18}$.

La actitud de Lowie no es extraña entre los historiadores de la antropología. Resulta extremadamente difícil para un antropólogo desprenderse de los dogmas científicos con los que realiza su tarea, incluso cuando ejerce no tanto de profesional de campo, como de historiador de su propia disciplina. Sin embargo, resulta cierto que algunas historias presentan una mayor flexibilidad para la aceptación de las corrientes metodológicas a estudiar, mientras que otras carecen de esta tolerancia y sólo admiten aquellos pensadores acordes con su línea epistemológica. Es tradicional en estos casos

16 I. C. JARVIE, «Epistle to the Anthropologists», American Antbropologist, 77 (1975), 253-266; p. 256.

17 Robert H. Lowie, Historia de la etnología (México: F.C.E., 1981), 10. Original 1937.

18 Ibid., p. 247. 
apelar a la historia de Marvin Harris como ejemplo de historiografía parcial en la elección de sus fuentes, y especialmente crítica para con las opciones distintas de la propia. No obstante, no es éste el único ejemplo, y posiblemente tampoco el más escandaloso que podemos encontrar. Por otra parte, es de agradecer que Harris exponga abiertamente sus objetivos desde el comienzo de su obra, lo que no suele ser frecuente: «La razón por la que pasaremos revista a las principales teorías antropológicas de los últimos doscientos años es la de probar que los antropólogos no han aplicado nunca consecuente ni consistentemente el principio del determinismo tecnoecológico y tecnoeconómico a toda la gran variedad de fenómenos con que están familiarizados. A pesar de lo cual, han contribuido poderosamente a desacreditar esa opción que ellos nunca eligieron» ${ }^{19}$. En cualquier caso, resulta evidente que la visión de la Ilustración que nos presenta Harris no pretende dar una muestra global del pensamiento de aquella época: «... los filósofos sociales del siglo XVIII fueron los primeros en sacar a la luz las cuestiones centrales de la antropología contemporánea y se esforzaron resueltamente, pero sin éxito, por formular las leyes que gobiernan el curso de la historia humana y la evolución de las diferencias y de las semejanzas socioculturales» ${ }^{20}$.

Para lograr su propósito, Harris no duda en citar todo pensador del siglo XVIII que tenga algo que ver con un esbozo de teoría materialista: Turgot, D'Holbach, La Mettrie, etc., son criticados con más o menos dureza, pero su tratamiento es más favorable que el dado a Rousseau, Montesquieu, etc. Pero no es sólo este dato el que nos da idea de los criterios de Harris; su rechazo de los pensadores anteriores a la publicación del libro de Locke An essay concerning buman understanding, encuentra las debidas excepciones cuando el carácter materialista del autor así lo justifica. Gracias a ello comprendemos que:

En realidad, en la cuestión de la evolución sociocultural la Ilustración se limitó a volver a colocar en una posición intelectualmente respetable una doctrina existente desde muy antiguo. Todo el pensamiento evolucionista de la llustración delata la influencia de Lucrecio, el gran poeta y filósofo materialista romano del siglo 1 d.C. En su poema De la naturaleza de las cosas, Lucrecio, que se inspiraba en otras ideas evolucionistas aún más antiguas, las expresadas por el griego Epicuro, alcanzó un nivel de comprensión de la evolución sociocultural y biológica que no sería igualado hasta dieciocho siglos más tarde ${ }^{21}$.

\footnotetext{
19 Marvin HARRIS, op. cit., p. 4.

20 Ibid., p. 7.

$21 \quad$ Ibid., p. 23.
} 
Realmente la historia que Harris ha escrito sólo se comprende dentro de su medio cultural y en la fecha de publicación de su primera edición, 1968: en un medio antropológico como el norteamericano, dominado por las interpretaciones emic de la cultura y con la mayor parte de los Departamentos de Antropología en poder de entusiastas de la escuela idealista en su versión postboasiana, estructuralista o «nueva etnografía». En este ambiente, Harris no sólo se ve obligado a demostrar que ha existido una tradición materialista desde tiempos seculares, sino que, además, el materialismo es una estrategia de investigación tan legítima como cualquier otra, y que puede dar mejores resultados. Esta es la línea en la que debe leerse su historia, y que, por otra parte, apoya totalmente lo que queríamos demostrar: se utiliza la historia como excusa para defender la propia metodología; lo importante no es la historia de la antropología en sí, sino que ésta resulte desveladora del «auténtico» pasado de la disciplina. En esta problemática adquieren sentido manifestaciones de paternidad intelectual como ésta: «El materialismo cultural es una estrategia no hegeliana cuyos presupuestos epistemológicos entroncan con las tradiciones filosóficas de David Hume y el empirismo británico, presupuestos que desembocaron en Darwin, Spencer, Tylor, Morgan, Frazer, Boas y el nacimiento de la antropología como disciplina académica» ${ }^{22}$. Pero también permite explicar comentarios sobre la situación y dominio académico de los Departamentos de Antropología en Estados Unidos:

Carece de sentido criticar al materialismo cultural en términos de un estado de cosas puramente imaginario en el cual todas las demás estrategias han sido eliminadas de algún modo, cuando en la realidad, el materialismo cultural no mantiene sino una posición subordinada y minorista en el seno del establishment de la ciencia social y es objeto de ataques por parte de numerosos críticos, situados, tanto a la derecha como a la izquierda en el espectro político ${ }^{23}$.

Sería injusto reducir el uso de la historia como argumento epistemológico a los manuales. También existen numerosos artículos, mucho menos pretenciosos o únicamente preocupados de un pequeño fragmento del pasado, que intentan narrar éste de acuerdo con las creencias metodológicas de su autor. Un ejemplo de este tipo es el que nos proporciona Leslie A. White. Durante muchos años White, formado en la tradición boasiana ${ }^{24}$, se enfrentó con los discípulos de Boas en defensa del evolucionismo de

22 Marvin HARRIS, El materialismo cultural (Madrid: Alianza Editorial, 1982), 14. Original 1971.

23 Ibid., p. 93.

24 Marvin HARRIS, op. cit. (1978), 553. 
Morgan. Su actitud de heredero de Morgan en un momento en que éste era denostado por la mayor parte de los antropólogos americanos, le obligó a acudir en defensa de su pensamiento una y otra vez. Pero los excesos a los que llegó pueden permitirnos confirmar la necesidad que tenía de aceptar un precursor a su medida. Los comentarios sobre Morgan, en lo que respecta a su actitud hacia la ciencia y la religión, no tenían tanta importancia para White como la influencia de esta imagen del viejo evolucionista para su teoría de la evolución; sólo así se explican párrafos como el que sigue, cuya última parte resulta significativa de los auténticos intereses de White:

La actitud de Morgan hacia la religión y la ciencia tiene, por supuesto, más significación que la meramente biográfica. Está íntimamente relacionada con el desarrollo de la antropología en América. Nuestra interpretación de esta historia y nuestra evaluación de la contribución de Morgan están en gran parte influidas por nuestra concepción del punto de vista filosófico de Morgan. Si vemos a Morgan como un hombre que «nunca se emancipó de su fondo teológico», como un «biblicista conservador», del cual todas sus investigaciones son «dominadas» por la religión, como un hombre incapaz por sí mismo de aceptar el darwinismo, no estamos pensando en muchas de sus contribuciones a la antropología. Si vemos a Morgan, como aparentemente hace el profesor Radcliffe-Brown, como un filósofo provinciano que mide toda la humanidad por las normas pequeño burguesas «de Rochester, N.Y.», probablemente no estamos teniendo una alta estima de sus logros científicos. Presentar a Morgan como un encabalgado teólogo antidarwiniano es una forma de desacreditar la teoría de la evolución en antropología cultural ${ }^{25}$.

Pero la soledad evolucionista que acompaña a White en la antropología americana de la época, no era buena consejera. Su defensa de Morgan iba, con frecuencia, más allá de la misma capacidad de la razón para contemplar los hechos con adecuada frialdad. Defendiendo de nuevo a Morgan (y a Tylor) de lo que consideraba una falacia antievolucionista, White no duda en mezclar a uno de los más señalados boasianos como era Lowie entre los que suponen incompatibilidad entre las teorías evolutivas y las difusionistas ${ }^{26}$. El resultado era un error notable de la escuela de Boas: «la respuesta es simple: la escuela de Boas ha confundido la evolución de la cultura con la historia cultural de los pueblos» ${ }^{27}$.

25 Leslie A. WHITE, «Morgan's attitude toward religion and science», American Antbropologist, 46 (1944), 218-230; p. 230.

26 Leslie A. WHITE, "Diffusion versus Evolution": An anti-evolutionist fallacy", American Antbropologist, 47 (1945), 339-356; p. 339.

27 Ibid., p. 343. 
La explicación de este hecho se basaba en que «Boas y la mayoría de sus discípulos han sido siempre ardientes antievolucionistas» ${ }^{28}$. La demostración de esta afirmación venía dada por una vieja revisión de las teorías etnológicas que hiciera Paul Radin; el mismo Radin que unos años antes afirmaba: «En los Estados Unidos, donde han sido hechos muchos de los mejores trabajos etnográficos, la dirección, desde los primeros días, era definitivamente antievolucionista y anti-histórica, la única excepción, por supuesto, era Lewis Morgan» ${ }^{29}$.

Leslie White había olvidado, en su intento por apropiarse de un Morgan a la medida, que ocho años antes de la publicación de su artículo, Lowie había hecho matizaciones al evolucionismo de Morgan en su A History of Ethnological Theory (1937). En la misma podemos encontrar señalizaciones diversas sobre la aceptación del difusionismo por Morgan: «Morgan no se dejó perturbar demasiado por los préstamos culturales, aunque admitió sin dificultad su existencia» ${ }^{30}$. Unas líneas después subrayaba Lowie: «Pero el caso de Pitt-Rivers nos ha demostrado que la creencia en un solo foco original de determinados fenómenos y la teoría evolucionista no se excluyen mutuamente. Efectivamente, el paralelismo general de Morgan fue reemplazado, en el tratamiento de dos de sus problemas principales, por su antítesis exacta» ${ }^{31}$.

No cabía la posibilidad de dudar respecto al conocimiento del difusionismo de Morgan por parte de Lowie. Hubiera bastado a White con leer el último capítulo de la historia de aquél para comprender este hecho. Allí afirmaba rotundamente Lowie: «Nadie ha negado nunca in toto el fenómeno de la difusión, y su importancia ha sido establecida en tal forma que ninguna sutileza la puede afectar» ${ }^{32}$.

Estas manifestaciones no debieron parecer suficientes a White; sin embargo, un observador más objetivo en sus planteamientos, después de subrayar el difusionismo que puede descubrirse en la obra de Morgan, ha minimizado el planteamiento antievolucionista que White pretendía ver en Boas: «... la culminación de la teoría de Boas no es tan anti-evolucionista como pretendía White, y, en cualquier caso, dentro del problema que tratamos aquí, la obra de Boas nos sitúa ante el mismo resultado que predo-

28 Ibid., pp. 350-351.

29 Paul RADIN, "History of Ethnological theories», American Antbropologist, 31 (1929), 9-33; p. 15.

30 Robert H. Lowle, op. cit., p. 78.

$31 \quad$ Ibid., p. 79.

32 Ibid., p. 305. 
minaba en La Sociedad Primitiva de Morgan: la supuesta unidad de la mente humana como explicación de las similitudes culturales» ${ }^{33}$.

No nos queda sino añadir que la búsqueda de este tipo de opciones ha sido frecuente en la historiografía de la antropología. Las historias y ejemplos aquí analizados evidencian esta característica, pero la mayor parte de las historias y artículos históricos anteriores a los años 60 , y bastantes de los posteriores, podían haber ocupado su lugar. La necesidad de buscar los propios precursores y fabricarlos a la medida ha sido una práctica frecuente en la historiografía antropológica. La historia, desde este punto de vista, ha sido víctima de las necesidades y disputas metodológicas entre las distintas escuelas antropológicas.

\section{HISTORIA, TELEOLOGIA Y OPCIÓN METODOLÓGICA}

Pero además de influir en la visión del ancestro con una valoración más o menos favorable del mismo, la opción metodológica del autor de la historia suele determinar el sentido de la antropología actual, pues al mostrar el progreso de la disciplina, se presenta la propia escuela como el punto culminante de este proceso.

Tradicionalmente, la historia de cualquier disciplina asume el hecho de que esa ciencia ha progresado. Se narran los distintos momentos en que nuevas aportaciones conceptuales determinan su avance. Se trata de un proceso diacrónico y acumulativo. La ciencia que llamamos antropología no es ajena a este hecho: las historias intentan mostrar las distintas formas de entender la disciplina que se han producido. Carecería de interés una historia que no cumpliera este requisito, si es que podría llamarse historia. El problema es que tal y como se ha entendido la historia de la antropología, no sólo se trata de explicar el pasado, sino también de mostrar cómo éste forma parte de un proceso que lleva supuestamente al predominio de la escuela a la que pertenece su autor.

La misma refutación que se ha producido entre los distintos autores de historias de la antropología muestra su relación con este hecho; se hace necesario desprestigiar las obras que ensalzan una versión rival de lo que debe ser la antropología para reafirmar la propia. Ya en 1937, Lowie expresaba el carácter deficiente de las historias que existían por no dar correcto detalle del proceso que debían narrar:

33 José Luis Garcfa Garcfa, y Luis Cencillo, Antropologia cultural: factores psiquicos de la cultura (Madrid: Guadiana, 1976), 404. Original 1972. 
Existen dos historias de la ciencia del hombre, pero ninguna ofrece un resumen adecuado de la evolución de la etnología. El profesor Alfred D. Haddon, ese veterano que tan justa estima merece, ha reunido en las 140 paginitas de su History of Antbropology (Londres, 1934) una cantidad asombrosa de nombres y fechas relacionadas con la prehistoria, la antropología física, la lingüística y la etnología; pero las limitaciones de espacio excluyeron todo intento de seguir el proceso de las ideas. Por su parte el libro de T. K. Penniman, A Hundred Years of Anthropology (Londres, 1935) da una importancia unilateral a los problemas de carácter biológico, y a la vez, es muy arbitrario en la admisión o exclusión de los asuntos relacionados con la etnología ${ }^{34}$.

Lo que le interesaba a Lowie era presentar una versión unificada del pensamiento antropológico. Mostrar que lo realizado en cada país bajo el nombre de etnología o antropología formaba parte, por encima de diferencias de detalle, de una misma ciencia. Para lograr este objetivo era fundamental criticar por eclécticas las historias que no contribuían a tal tarea; Regna Darnell ha argumentado a favor de este supuesto concluyendo «que el proceso de profesionalización, produciendo lo que rotulamos hoy como antropología boasiana, estaba, en lo esencial, completo hacia 1920 en Norteamérica. Como la disciplina creció en tamaño y diversidad de focos, llegó a ser imperativo demostrar su unidad en perspectiva histórica» ${ }^{35}$.

Esta exigencia narrativa, que obliga a dar debida cuenta del pensamiento antropológico que ha precedido al momento en que se escribe la historia, deja de existir en lo que se refiere a las diversas corrientes de investigación coetáneas al autor de la misma. El caso más frecuente, que se registra en la mayor parte de las historias de la antropología escritas por antropólogos, y que hemos podido observar con anterioridad, es el de conceder primacía metodológica a la línea que suscribe el autor. Sin embargo, también conviene llamar la atención sobre el matiz teleológico que adquieren estas obras: se ensalza la propia opción del autor, apuntando que es el último avance de la disciplina, y que tanto las opciones rivales como los desarrollos futuros deberán contar con sus aportaciones. Esto es lo que se hace evidente una vez más en la Historia de la Etnologia de Lowie: «¿Cuál es, pues, la perspectiva de la etnología? Las esperanzas para un desarrollo futuro descansan en el mantenimiento de la manera universalista y a la vez objetiva con que Tylor y Boas enfocaron sus problemas; sean cuales fueren las preferencias de cada investigador individual, nuestra ciencia como conjunto no

34 Robert H. LowIE, op. cit., p. 9.

35 Regna DARnell, «History of Anthropology in historical perspective», Annual Review of Anthropology, 6 (1977), 399-417; p. 401. 
puede descuidar ningún aspecto de la vida social, como si fuera intrínsecamente inferior a los demás» ${ }^{36}$.

Pero la adecuada confirmación de lo que afirmamos debe proporcionarla un estudio comparativo de historias coetáneas. En cada una de ellas no sólo debe primar la línea metodológica del que hace la historia sino que además debe presentar su concepción de la disciplina como el logro más importante que ha producido la antropología en los últimos tiempos. Esto es lo que ocurre en la breve introducción histórica de Beattie. El autor reconoce que «... lo que me interesa es hacer hincapié en que los dos más importantes esfuerzos a partir de los cuales se ha levantado la estructura de la moderna antropología social son, por una parte, la tradición buscadora de hechos, empírica y etnográfica, representada por la antropología británica y por gran parte de la alemana y la norteamericana, y por otra, el intelectualismo analítico e "integralista" de la filosofía social francesa” ${ }^{37}$.

Este reconocimiento integrador hecho en 1964, tiene gran importancia, pero poco después las aguas vuelven a su cauce al reconocer Beattie que «no obstante, en la actualidad, el acento recae en lo esencialmente empírico y funcional» ${ }^{38}$.

Esta es la línea apropiatoria que registran la mayor parte de las historias. En la misma época, 1964, Godfrey Lienhardt publica su Antropología Social, respondiendo a un encargo que en 1956 le hiciera la Universidad de Oxford ${ }^{39}$. La calidad de su capítulo histórico sobresale por encima de los de otras introducciones similares. Lo que mejor puede ilustrar el hecho que venimos comentando es que Lienhardt dedica cinco páginas de un total de cuarenta y ocho a resaltar la importancia de Durkheim, conocido por su influencia intelectual sobre Radcliffe-Brown, maestro de Lienhardt ${ }^{40}$.

El aspecto comparativo de lo que venimos afirmando nos lo pueden proporcionar otras dos obras cuyos autores comparten muy distintas líneas metodológicas. Nos referimos a la historia de Harris, publicada, como se ha dicho, en 1968 y de tendencia materialista, y la historia, mucho más breve que la anterior, de Pietro Scarduelli, publicada originalmente en 1976,

36 Robert H. LowIE, op. cit., p. 354.

37 John BEATTIE, Otras culturas. Objetivos, métodos y realizaciones de la Antro. pologia Social (Madrid: F.C.E., 1978), pp. 26-27. Original 1964.

38 Ibid., p. 29.

39 Fermín del PINo DfAz, «El nacionalismo en la historia de la ciencia, el caso de la etnología», Ethnica, 12 (1976), 95-125; p. 119.

40 Godfrey Lienhardt, Antropología social (México: F.C.E., 1974), 56-61. Original 1964. 
y de tendencia marcadamente estructuralista, como muestra la dedicación de su autor al estudio de aspectos diferentes de la obra de Lévi-Strauss ${ }^{41}$.

La historia de la antropología de Harris es tan conocida que parece superfluo intentar decir algo de ella. El éxito de ventas de la misma sólo se explica por la claridad con que expresa su contenido, y por haber sido objeto del interés de un público que rebasa el número de los preocupados por la antropología. La habilidad que caracteriza la forma de exponer sus ideas, unida a un atractivo estilo literario, han hecho de la historia de Harris un libro de fácil lectura. Los conocimientos que muestra de la tradición boasiana, examinada con crítico detallismo, ofrecen su contrapunto en el análisis del estructuralismo francés y en el de la antropología social británica, no tan afortunados en su presentación. La defensa de los intereses materialistas en antropología nunca ha contado con mejor publicista: a un nivel superficial, la magia del lenguaje enmascara la exposición de las teorías. A los efectos de mostrar el carácter teleológico de este libro, el mejor dato que podemos utilizar es la imagen que muestra su índice: los dos últimos capítulos están dedicados a exponer la teoría materialista que Harris defiende. El autor no duda del éxito de esta línea entre las nuevas generaciones de antropólogos:

La lista de antropólogos que se han inspirado directamente en el tratamiento que Steward dedica a las interacciones tecnoecológicas y tecnoeconómicas es proporcionalmente mayor e incluye hasta la fecha a muchos antropólogos más jóvenes que aceptan ya la ecología cultural como obvia y que sólo reconocen la aportación de Steward en la medida en que la critican para, basándose en datos nuevos, refutar algunas de sus explicaciones ecológicas concretas.

Nada sería más contrario a las coordenadas generales desde las que se ha escrito este libro que el explicar el reciente auge de los estudios ecológicos como una resultante de la influencia personal de Steward. El creciente interés por las relaciones tecnoecológicas y tecnoeconómicas es el reflejo de un vasto movimiento que se propone dar más fuerza a las credenciales científicas de la antropología cultural en el seno de las prestigiosas y sólidamente fundamentadas ciencias naturales ${ }^{42}$.

Visto este carácter teleológico de las distintas historias del pensamiento antropológico, nada de extraño tiene que un firme defensor del estructuralismo, como Pietro Scarduelli, dedique más espacio a analizar el pensamiento de Lévi-Strauss (trece páginas), que a ningún otro movimiento o figura

41 Pietro Scarduelli, Lévi-Strauss y el Tercer Mundo (Madrid: Ed. Villalar, 1977). Original 1976.

42 Marvin HARRIS, op. cit. (1978), 567. 
en su breve historia ${ }^{43}$. Además, no puede evitar una confirmación de la primacía estructuralista cuando al final del libro dedica poco más de tres páginas a las nuevas orientaciones de la antropología. De hecho, esta última parte de su estudio se muestra como una ratificación de la aceptación de nuevos movimientos que convergen con el estructuralismo (a lo que dedica la última página del libro dentro de esta parte final que venimos comentando). Por ello, no puede sorprendernos la siguiente afirmación:

Sin negar la vitalidad de la escuela anglosajona, los desarrollos más interesantes de la antropología se han registrado en los últimos años en Francia, merced al encuentro (en el doble sentido de coincidencia y contraste) entre el estructuralismo y el marxismo ${ }^{44}$.

Creo que con este último autor se hace evidente el carácter progresivo que poseen las historias de la antropología, encaminado en su parte final a demostrar que el último logro de la disciplina es el que aporta la línea metodológica del que hace la historia. En este sentido, la utilización de varios tipos de historias, de distintas épocas, con autores pertenecientes a diferentes escuelas, pero lo suficientemente cercanos en el tiempo como para conocer similares líneas de investigación, resulta concluyente. Por otra parte, este hecho confirma, una vez más, los intereses y la subjetividad que envuelven la mayor parte de los trabajos historiográficos de nuestra disciplina.

\section{4. ¿QUIÉN DEBE ESCRIBIR LA HISTORIA DE LA ANTROPOLOGIA?}

Ante esta perspectiva, parece que la única solución es defender la existencia de una historiografía de la antropología independiente de los propios antropólogos, hecha por historiadores especializados, ajenos a las polémicas metodológicas propias de la disciplina que se trata de historiar; sin embargo, no todos los autores están de acuerdo con esta solución. Desde el año 1962, en que se reúne una Conferencia sobre Historia de la Antropología en Nueva York, con la participación de antropólogos e historiadores de la ciencia, el debate sobre si la historia de la antropología debe ser escrita por antropólogos o por historiadores, cobra actualidad ${ }^{45}$.

43 Pietro SCARDUell, Introducción a la antropología cultural (Madrid: Ed. Villalar, 1977). Original 1976.

44 Ibid., p. 82.

45 Dell HyMes, op. cit. 
No debemos conformarnos con el argumento que ve en el dominio del mayor número de cátedras y controles académicos la única causa de la asignación de la historia de la antropología a la profesión de antropólogo. Dirigirse a este tipo de razones sería desvirtuar un debate que tiene sus antecedentes en la sociología del conocimiento. Merton ha estudiado el tipo de situación creada en el análisis de minorías o de grupos marginados (negros, mujeres), ante la perspectiva de que debían ser personas pertenecientes a estos grupos las que realizaran estudios que los tuvieran por objeto ${ }^{46}$. Se puede añadir que los argumentos utilizados para apoyar en uno u otro sentido la perspectiva de «los de adentro» y «los de afuera», recuerdan en gran medida lo que se dice respecto a la necesidad de que la historia de la antropología sea hecha por historiadores o por antropólogos. La defensa del antropólogo como historiador de su ciencia ha sido realizada por Llobera:

Por lo que respecta a la historia de la antropología y de las ciencias sociales en general, no se trata simplemente de una cuestión de exponer los distintos momentos de su racionalidad científica en la correspondiente matriz social, sino de demostrar sus implicaciones directas en la teoría social contemporánea. Como veremos más adelante, este aspecto justifica plenamente mi defensa de que la historia de la antropología no puede quedar solamente en manos de anticuarios o de historiadores especializados (si algún día llegan a existir). Quiero decir que debe merecer la atención práctica de personas formadas en la disciplina antropológica según las teorías actuales y en el contexto de los problemas de su quehacer académico, ordinario ${ }^{47}$.

La dificultad que surge de una historia escrita por antropólogos ha sido analizada por Stocking en su artículo sobre presentismo e historicismo: «La orientación del historiador aproximándose a la historia de las ciencias de la conducta tenderá a ser "historicista" y su postura motivacional "afectiva"... La aproximación del científico profesional de la ciencia social, por otra parte, es probablemente más liberal [whiggish] o más ampliamente, "presentista", y su postura motivacional "utilitaria"” ${ }^{48}$

Sin embargo, puede reconocerse un movimiento de interés por la historia de la antropología como elemento formativo para los antropólogos.

46 Robert K. MERToN, «Las perspectivas de "los de adentro" y "los de afuera"», La sociología de la ciencia (Madrid: Alianza Editorial, 1977), 2 vols., 156-201. Original 1972.

47 Josep R. Llobera, Hacia una historia de las ciencias sociales. El caso del materialismo bistórico (Barcelona: Anagrama, 1980), 17.

48 George W. STocking, Jr., op. cit., p. 6. 
En esta línea se mueven autores como Oscar Lewis ${ }^{49}$ y W. N. Fenton: «La antropología científica tiene ahora cien años. No es posible para los estudiantes conocer a sus fundadores, y muy pocos de la primera generación de antropólogos formados por Boas están todavía enseñando. Pero un conocimiento de la historia de la etnología americana debería formar parte de la libre educación de los antropólogos» ${ }^{50}$.

También se intenta, más recientemente, recoger el reto de Stocking, y se aboga por una historia de la antropología más objetiva, distante de las mistificaciones al uso:

Es tiempo para los antropólogos de hacer auténtica historia de la antropología, de cesar de tratar a sus propios predecesores de la manera en que acusaron a estos predecesores de tratar a los salvajes, esto es, como torpes, estúpidos, etc., cesar, en otras palabras, de transmitir mitos orales acerca de la historia antropológica que sabe a sillón en la terraza, y emprender en serio algún trabajo de campo, con sus penas y recompensas, de la historia de la antropología misma ${ }^{51}$.

En definitiva, se reconoce la importancia de la historia de la antropología como elemento formativo de las nuevas promociones de antropólogos, permitiendo que la historia sea más objetiva y prestando atención a las auténticas controversias y no a la anécdota alejada de la dimensión que corresponde a una ciencia. La polémica de «los de adentro» y «los de afuera» era cerrada en el análisis de Merton con este comentario: «Un artículo como éste no necesita ninguna peroración. Sin embargo, he aquí la mía: es menester que os unáis "los de adentro" y "los de afuera". No tenéis nada que perder, excepto vuestras pretensiones. En cambio, tenéis un mundo de comprensión por ganar» ${ }^{52}$.

La solución respecto al dilema de quién ha de escribir la historia de la antropología viene dada también en términos conciliadores:

... lo importante no es el origen particular del erudito, sino que conozca bastante de ambas, ciencia e historia. Los historiadores pueden aprender antropología; los antropólogos pueden aprender historia.

Creo que esta solución no sólo es mejor, sino necesaria. Debería añadir únicamente que la cualificación no debería ser unilateral, que existan no sólo histo-

49 Oscar LEWIS, «Controles y experimentos en el trabajo de campo», La Antropo. logía como ciencia, comp. Josep R. LLOBERA (Barcelona: Anagrama, 1975), 97-127; p. 104. Original 1953.

50 William N. Fenton, "The training of historical ethnologist in America», American Anthropologist, 54 (1952), 328-339; p. 330.

51 I. C. JARVIE, op. cit., p. 263.

52 Robert K. MERTON, op. cit., p. 201. 
riadores que aprendan antropología, sino también antropólogos, algunos, que aprendan historia. En breve, tendremos que prepararnos para formar algunos antropólogos como especialistas en historia de la antropología ${ }^{53}$.

Lo que viene a defender esta propuesta es, en definitiva, que el historiador de la antropología esté familiarizado con la disciplina que debe de historiar. Sea originariamente antropólogo o historiador, lo importante es que conozca lo suficiente de ambas ciencias como para llevar a cabo una labor digna. En este mismo sentido hablaba Stocking de la necesidad de que el historiador de la antropología conozca el pensamiento antropológico, y ponía el énfasis no tanto en su origen disciplinar (historiador o antropólogo), como en la actitud que debía adoptar al realizar su trabajo:

El historiador de la antropología, en absoluto su fundamento disciplinario, siempre deberá estar familiarizado con el pensamiento antropológico del presente sobre los problemas que está investigando históricamente, ya que en última instancia una de las más importantes metas de su investigación es contribuir a nuestra comprensión de los contextos históricos y de los procesos de los que la antropología actual ha emergido. Pero incluso en esta actividad su compromiso como historiador es hacia el pasado, y hacia el histórico más que al polémico presente ${ }^{54}$.

Con este párrafo puede confirmarse que una nueva especialización recorre los Departamentos de Antropología a la búsqueda de una institucionalización que asegure su porvenir. Tal vez, la misma especialización que caracteriza desde hace tiempo a la antropología, colabore en la emergencia y difusión de su propia historia; mientras tanto, sólo nos resta preocuparnos por hacer una historia real, lo más objetiva posible, preocupada por desvelar el auténtico pasado, y no el que mejor se acomoda a nuestros deseos. Una historia que no sea mera excusa para la defensa de cualquier interés ajeno a la historiografía, una historia, en definitiva, cuyo eje central sea ella misma. En esta labor, el rito iniciático del trabajo de campo deja de ejercer su carácter selectivo; el historiador de la antropología formará parte de un gremio especializado tal vez más cercano a la historia del pensamiento o a la historia de las ideas que a la propia antropología.

\section{Francisco Castilla URbano}

53 Dell Hymes, op. cit., p. 299.

54 George W. Stocking, Jr., "Cultural Darwinism" and "Philosophical Idealism" in E. B. Tylor: A Special Plea for Historicism in the History of Anthropology", Southwestern Journal of Anthropology, 21 (1965), 130-147; p. 143. 
La historia de la antropología ha sido una disciplina ocupada tradicionalmente por antropólogos retirados del trabajo de campo, que aplicaban en ésta sus convicciones metodológicas; el resultado ha sido la disparidad de versiones historiográficas. Sólo una historia de la antropología hecha por auténticos historiadores, independientemente de su origen particular, la antropología o la historia de la ciencia, conseguirá hacer de aquélla una disciplina objetiva.

The history of anthropology has traditionally been studied by anthropologists no longer actively involved in fieldwork, who have used it to put forward their own methodological positions. The result has been the wide variety of different versions of that history. Only a history of anthropology written by historians, regardless of whether they come from anthropology or the history of science, will be able to make the history of anthropology an objective discipline. 